\title{
Laparoscopic Treatment of Traumatic Intraperitoneal Bladder Rupture
}

\author{
Andre A. Figueiredo, Jose G. T. Tostes, Miguel V. M. Jacob \\ Santa Casa de Misericordia, Juiz de Fora, Minas Gerais, Brazil
}

\begin{abstract}
Traumatic intraperitoneal bladder rupture requires surgical suture and bladder drainage. In stable patients the laparoscopic approach is the best short recovery and less traumatic treatment allowing visualization of the entire peritoneal cavity to exclude others lesions. We present one case of successful laparoscopic treatment of this entity.
\end{abstract}

Key words: bladder; wounds and injuries; laparoscopy

Int Braz J Urol. 2007; 33: 380-2

\section{INTRODUCTION}

Traumatic intraperitoneal bladder rupture requires surgical suture and bladder drainage. In stable patients the laparoscopic approach is the best short recovery and less traumatic treatment allowing visualization of the entire peritoneal cavity to exclude others lesions.

\section{CASE REPORT}

A 20-year-old female presented to hospital with complains of abdominal pain and hematuria after alcohol ingestion and a two floors fall with ventral collision. She was hemodynamically stable and the radiological evaluation showed a right pubic ramus fracture and free peritoneal liquid, discontinuity of bladder wall and normal kidneys through sonography (Figures-1 and 2). The cystography made evident an intraperitoneal bladder rupture (Figure-3).
The patient was submitted to laparoscopic exploration with three trocars, a $10 \mathrm{~mm}$ umbilical trocar and two $5 \mathrm{~mm}$ trocars, one in each iliac fossa. The surgeon's position was on the patient's left side to allow inspection of pelvic structures. The laparoscopic findings were blood and urine in the peritoneal cavity, a $5 \mathrm{~cm}$ bladder rupture in the dome and no other lesions. The cavity was cleaned and the bladder sutured with a continuous one layer 3-0 polyglactin suture.

The patient was discharged from hospital in the 5 th postoperative day due to the need of bed rest for pelvic fracture consolidation. Fourteen days after surgery the bladder catheter was removed with favorable evolution.

\section{COMMENTS}

Treatment recommendations for bladder rupture are well established as bladder catheter for ret- 


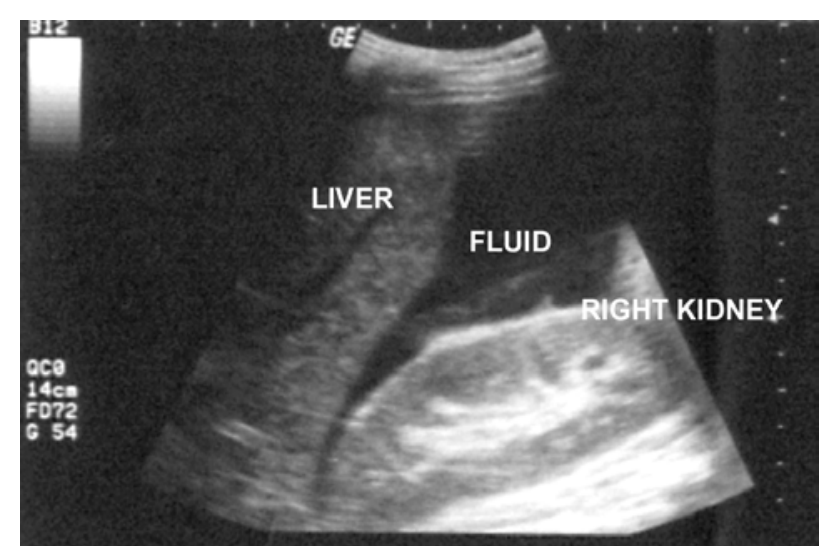

Figure 1 - Sonography showing free intraperitoneal fluid.

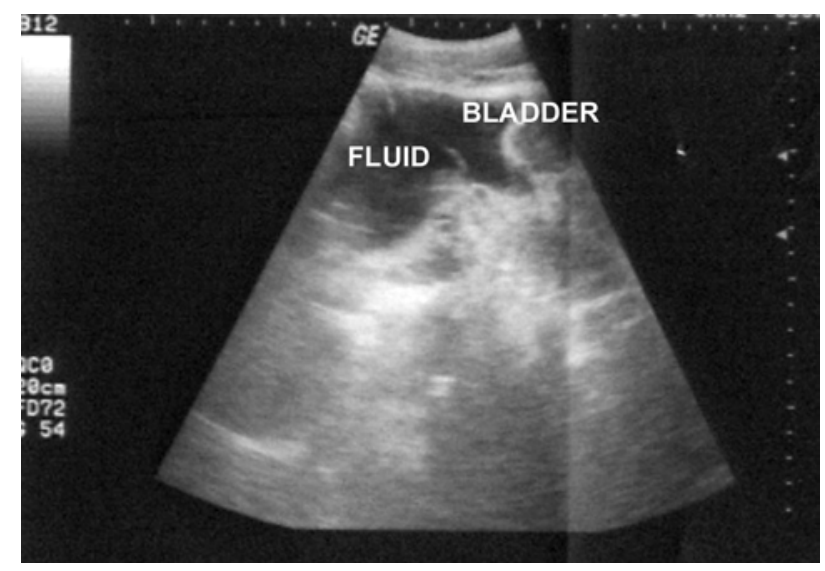

Figure 2 - Sonography showing discontinuity of peritoneal bladder wall.

roperitoneal perforations and cystorrhaphy for the intraperitoneal ones (1).

Laparoscopy is a minimally invasive technique to diagnose and eventually treat abdominal trauma. It can avoid laparotomy in $63 \%$ of the cases, decreasing its associated morbidity (2). In hemodynamically stable patients without diffuse peritonitis, the diagnostic laparoscopy can be used in stab wounds, gunshot wounds with questionable peritoneal penetration and in blunt trauma with free peritoneal fluid or equivocal physical examination. In the presence of simple and accessible injuries the therapeutic laparoscopy is performed. Bladder intraperitoneal rupture is of easy

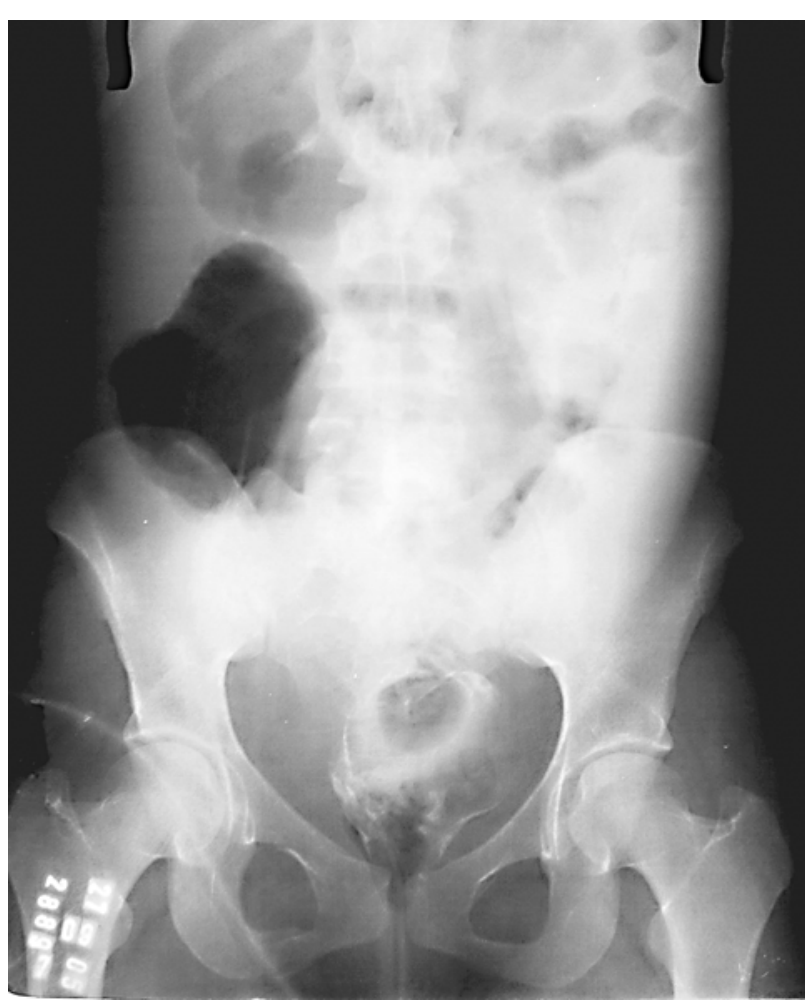

Figure 3-Cystography showing intraperitoneal bladder rupture.

correction through laparoscopic approach (2) and in the eventually presence of concomitant extraperitoneal rupture, the bladder drainage after surgery can treat it, if the rupture is not complex, avoiding an open surgery.

Laparoscopic repair of intraperitoneal bladder perforation was first described in 1994 and since then, a few cases of such approach have been reported to treat traumatic, spontaneous and iatrogenic bladder rupture, avoiding laparotomy (3).

The aim of this report was to stimulate the practice of laparoscopic exploration in stable trauma and remember the urologists the laparoscopic approach to any form of peritoneal bladder rupture.

\section{CONFLICT OF INTEREST}

None declared. 


\section{REFERENCES}

1. Gunnarsson U, Heuman R: Intraperitoneal rupture of the urinary bladder: the value of diagnostic laparoscopy and repair. Surg Laparosc Endosc. 1997; 7: 53-5.

2. Gorecki PJ, Cottam D, Angus LD, Shaftan GW: Diagnostic and therapeutic laparoscopy for trauma: a tech- nique of safe and systematic exploration. Surg Laparosc Endosc Percutan Tech. 2002; 12: 195-8.

3. Matsui Y, Ohara H, Ichioka K, Terada N, Yoshimura K, Terai A: Traumatic bladder rupture managed successfully by laparoscopic surgery. Int J Urol. 2003; 10: 27880.

Accepted after revision: October 24, 2006

\section{Correspondence address:}

Dr. André Avarese de Figueiredo

Rua Irineu Marinho 365 / 801 - B1 3

Juiz de Fora, MG, 36021-580, Brazil

E-mail: andreavaresef@hotmail.com 